\title{
A study to evaluate the use of Information and Communication Technology by Sri Lankans to gather information on sexual and reproductive health
}

\author{
S. Tissera \\ I.N. Jayasinghe \\ A.I.K. Mahanama \\ R. Nisanthan \\ A.S.R. Pathiratne \\ P. Siriwardena \\ Family Planning Association, Sri Lanka.
}

Contact e-mail address: imalajay@gmail.com

eHealth Sri Lanka 2010,1(suppl.1):S25

DOI: http://dx.doi.org/10.4038/sljbmi.v1i0.3570

Only the Abstract is available

\begin{abstract}
Introducton: ICT can be used as a reliable source of information to provide answers for various questions regarding Sexual and Reproductive (SRH) issues in the Sri Lankan community. Keeping this in mind Family Planning Association of Sri Lanka developed 'Happylife Contact Centre'.

Objective: To describe the usage of ICT by various demographic parameters in the Sri Lankan population and to identify and describe the common SRH issues present in the community.

Methodology: A descriptive cross sectional study carried out at the 'Happylife Contact Centre'. All who contacted the 'Happylife Contact Centre' over a period of five months were included. Interviewer administered client information sheet was used.

Results: Number of client information sheets filled were 4074. Telephone calls were the main method of gaining information ie. 72.82 per cent whereas 16.89 per cent used e-mails, chat and skype. SMS had been used by 10.29 per cent. 22.38 per cent were between 19 to 25 years and 19.95 per cent were between 26 to 32 years. 60.72 per cent were males and 19.67 per cent were females. 40.57 per cent were married and 28.64 per cent were unmarried. 27.78 per cent had a query on family planning and 9.79 per cent on emergency contraceptives. 4.86 per cent had querries on premature ejaculation, 1.18 per cent on vaginismus 3.36 per cent on size of the penis and 2.3 per cent on erectile dysfunction.

Conclusion: Majority used telephone calls as the method of contact. It was males and married couples who connected with 'Happylife Contact Centre'. Most common age group to have issues regarding SRH was 19 to 25 years (young adults/ youth). The most common SRH problem was on family planning methods and sexuality issues. Information Communication Technology is a useful tool in providing SRH information and education in Sri Lanka.
\end{abstract}

Keywords - SRH issues, Family Planning, young adults, sexual and reproductive health 